\title{
Immunohistochemical Study of Amelogenin Binding Proteins in an Amelogenin Point Mutation Mouse
}

\author{
Estudio Inmunohistoquímico de Proteínas de Unión de la Amelogenina \\ en un Ratón con Mutación Puntual de Amelogenina
}

\author{
Naoko Otawa-Kamogashira' ${ }^{1}$ Yuko Matsuda ${ }^{1}$; Masaaki Takezaki ${ }^{1}$; \\ Yuji Hatakeyama ${ }^{2}$; Sachio Tamaoki ${ }^{1}$ \& Hiroyuki Ishikawa ${ }^{3}$
}

OTAWA-KAMOGASHIRA, N.; MATSUDA, Y.; TAKEZAKI, M.; HATAKEYAMA, Y.; TAMAOKI, S. \& ISHIKAWA, H. Immunohistochemical study of amelogenin binding proteins in an amelogenin point mutation mouse. Int. J. Morphol., 37(2):522-532, 2019.

SUMMARY: Amelogenin is one of the enamel matrices secreted by ameloblasts. A mutation of the amelogenin gene can cause hereditary dental enamel defects known as amelogenesis imperfecta (AI). Since lysosome-associated membrane protein-1 (LAMP-1), -3 (LAMP-3), and 78kDa glucose-related protein (Grp78) were identified as binding proteins of amelogenin, several studies have suggested the involvement of these binding proteins with the cell kinetics of ameloblasts in normal or abnormal conditions. The purpose of this study is to investigate the distribution of these amelogenin binding proteins in the ameloblast cell differentiation of mice with a point mutation of the amelogenin gene (Amelx*). The incisors of Amelx* mice had a white opaque color and the tooth surface was observed to be rough under a scanning electron microscope. Among the sequential ameloblast cell differentiation in the Amelx* mice, the shape of ameloblasts at the transition stage was irregular in comparison to those in wild-type (WT) mice. Immunostaining of Grp78 revealed that the whole cytoplasm of the transition stage ameloblasts was immunopositive for Grp78 antibody, while only the distal part of cell was positive in the WT mice. Furthermore, in the Amelx* mice, the cytoplasm of the transition stage ameloblasts was immunopositive for LAMP-1 and LAMP-3. These results suggest that Amelx* may cause the abnormal distribution of amelogenin binding proteins in the cytoplasm of ameloblasts.

KEY WORDS: Amelogenin; Amelogenesis imperfecta; 78kDa glucose-related protein (Grp78); Lysosome-associated membrane proteins (LAMPs).

\section{INTRODUCTION}

Tooth enamel is the most highly mineralized tissue in the body and it is a unique tissue that differs from other types of hard tissue since tooth enamel is formed by ameloblasts that are derived from the dental epithelium. During the formation of dental enamel, ameloblasts secrete several enamel matrix proteins, including amelogenin, ameloblastin and enamelin. Amelogenin, the most abundant enamel matrix protein, is transcribed from the Amelx gene, which is located on the $\mathrm{X}$ chromosome. During the transcription of the Amelx gene, at least 15 mRNA alternative splicing isoforms of amelogenin are secreted in mice. M180 is the most abundant amelogenin isoforms and leucin - rich amelogenin peptide (LRAP) is one of the abundant amelogenin isoforms. During enamel secretion and maturation (Haruyama et al., 2010), these secreted amelogenins are degraded by proteinases such as matrix metalloproteinase-20 (MMP-20) and kallikrein 4 (KLK4) into various smaller amelogenin peptides, including tyrosinerich amelogenin peptide (TRAP), and amelogenin as well as other organic matrices in the enamel, are almost totally removed during the mineralization of enamel before tooth eruption.

Inherited defects of dental enamel, known as amelogenesis imperfecta (AI), can be divided into 3 major categories based on the quantity and quality of the enamel: hypoplasia, hypocalcification, and hypomaturation (Witkop, 1988). Many patients with AI diseases only exhibit enamel defects, while others show systemic manifestations (Herzog et al., 2015). Most cases human AI are caused by mutations of Amelx gene and it has been reported that mice with a point mutation of TRAP exhibit AI (Barron et al., 2010).

\footnotetext{
${ }^{1}$ Section of Orthodontics, Fukuoka Dental College, Japan.

${ }^{2}$ Section of Functional Structure, Fukuoka Dental College, Japan.

${ }^{3}$ Fukuoka Gakuen Incorporated Educational Institution, Japan.
} 
Lysosomes are cellular organelles that are involved in endocytosis, phagocytosis, and autophagy. Lysosomes composes two classes of proteins: acid hydrolases and lysosomal membrane proteins. The most abundant lysosomal membrane proteins are lysosomal-associated membrane protein-1 (LAMP-1, CD107a), LAMP-2 (CD107b), and LAMP-3 (CD63). The LAMPs are not only present in the lysosome membrane but also in endosomes, phagosomes and on cell surfaces (Saftig \& Klumperman, 2009). Since LAMP-1 and LAMP-3 are identified as binding partners for mouse amelogenin (Zou et al., 2007), several studies have reported that LAMP-1 located in the cell membrane binds to amelogenin and that it may be a signaling receptor of amelogenin (Le et al., 2007; Zhang et al., 2010).

$78 \mathrm{kDa}$ glucose-related protein (Grp78) is a member of heat shock protein 70 and it is considered to be an endoplasmic reticulum (ER) chaperone that facilitates the transport of newly synthesized proteins into the ER lumen, protein folding, protein quality control, $\mathrm{Ca}^{2+}$ binding and regulating ER stress signaling (Daugaard et al., 2007). It has been increasingly recognized that ER stress is associated with multiple biological processes, including inflammation, bone loss, cell apoptosis, and extracellular matrix degradation (Bai et al., 2016). In hard tissue formation, it has been reported that Grp78 plays important role in the osteogenesis marker gene expression and cell proliferation (Fukuda et al., 2013). In addition, under conditions of morbidity, the expression of Grp78 was found to be increased in ameloblasts involving ER stress induced by fluoride (Zhang et al., 2016), which causes fluorosis enamel.

Exposure to high levels of fluoride leads to endoplasimic reticulum stress, in which the protein expression of Grp78 has been observed to increase in ameloblast. In addition exposure fluoride causes fluorosis enamel.

In this study we attempt to clarify the distribution of these amelogenin binding partners in the amelogenin mutation mouse, a mouse model of AI.

\section{MATERIAL AND METHOD}

Animals. Seven pairs of female heterozygous mutant mice (D2;B6-Rgsc888/Rbrc [M100888]) and male wild-type (WT) mice was obtained from RIKEN. Before obtaining the mice, the mutation of the Amelx gene was confirmed by RIKEN. This same mutant mouse line with the mutation of the Amelx gene was described in a previous study (Barron et al.). All animal studies conformed to guidelines approved by the Animal Experiment Committee of Fukuoka Dental
College, Fukuoka, Japan. Among the first generation of these mouse pairs, the most severe AI appeared on the incisors of hemizygous (AmelxX*/Y) mutant male mice. These mice were used as Amelx point mutation (Amelx*) mice, while male mice without AI on the incisors were used as WT mice, based on previous studies (Barron et al.).

Scanning Electron Microscopy. The tooth surface microstructure was evaluated using a scanning electron microscope (SEM) (JCM-6000 Plus, JEOL, Tokyo, Japan). The mandibles of WT and Amelx* mice (12-week-old) were dissected and fixed by $4 \%$ paraformaldehyde (PFA) in phosphate-buffer saline (PBS) at $\mathrm{pH}$ 7.4. After fixation, the mandibles of each mouse were washed using distilled water and dried in air. Each incisor with alveolar bone was observed under the SEM $(10.00 \mathrm{kV})$ without any metal coating. All images were obtained using a secondary electron detector.

\section{Tissue Preparation and Immunofluorescence Staining.} Tissue preparation and immunofluorescence staining were performed according to previously reported methods with minor modifications (Hatakeyama et al., 2014). WT and Amelx* mice (10-week-old) were anesthetized and perfused with $4 \%$ PFA in 0.1M PBS, pH 7.4. After dissection, the mandibles were fixed in $4 \%$ PFA in $0.1 \mathrm{M}$ PBS for $24 \mathrm{~h}$, decalcified in $10 \%$ EDTA and 0.01 M PBS (pH 7.4) for 4 weeks at $4{ }^{\circ} \mathrm{C}$, dehydrated in a graded ethanol series, embedded in paraffin, and serially sectioned into coronal sections (thickness: $4 \mu \mathrm{m}$ ). The sections were stained with hematoxylin and eosin (H-E) using standard protocols. Serial adjacent sections were provided and immunostained for LAMP-1 and Grp78.

The following primary and secondary antibodies were used in this study: rabbit-polyclonal to mouse LAMP-1 (Abcam, Cambridge, UK), rabbit-polyclonal to mouse LAMP-3 (Proteintech, Rosemont, IL, USA), and rabbitpolyclonal to mouse Grp78 (Abcam, Cambridge. UK), and goat anti-rabbit IgG secondary antibody conjugated to Alexa Fluor 594 (Molecular Probes, Eugene, OR, USA).

Immunostaining of these primary antibodies was performed according to previously reported methods with minor modification (Hatakeyama et al.). Briefly, sections were deparaffinized with xylene and rehydrated by decreasing concentrations of alcohol. For LAMP-1 and -3, to retrieve antigens on the sections, the sections were treated with $0.01 \mathrm{M}$ sodium citrate buffer, $\mathrm{pH} 6.0$ at $98{ }^{\circ} \mathrm{C}$ for 20 min and then washed three times for 5 min with PBS. For Grp78, antigen retrieval was not performed. Each primary antibody was diluted with PBS to $1 \mu \mathrm{g} / \mathrm{mL}$, and added to each section. The sections were incubated in the dark for $24 \mathrm{~h}$ at $4{ }^{\circ} \mathrm{C}$ and then washed three times for $3 \mathrm{~min}$ with 
PBS. The immunoreaction was visualized on the sections with secondary antibody diluted to $10 \mu \mathrm{g} / \mathrm{mL}$ at room temperature for one hour in the dark. After washing in PBS, to visualize the plasma membrane, the Golgi area and Tomes processes of the ameloblasts at each stage of cellular differentiation (Akita et al., 1988; Kagayama et al., 1997; Chazotte, 2011), the sections were then incubated with wheat germ agglutinin (WGA) conjugated fluorescein isothiocyanate (FITC) (J-Chemical, Tokyo, Japan) diluted $10 \mu \mathrm{g} / \mathrm{mL}$ for $10 \mathrm{~min}$ at room temperature. 4', 6-diamidino2-phenylindole (DAPI) (Vector Laboratories, Burlingame, CA, USA) was used for counterstaining and the sections were immediately mounted for observation.

\section{RESULTS}

To check the phenotype of 12-week-old Amelx* mice, we observed the enamel surface under an SEM. The macroscopic observation of the incisors of the mice with the point mutation showed a white opaque enamel surface (Fig. 1B), while the incisors of the WT mice were clear brown (Fig. 1A). Scanning electron microscopy revealed that the enamel surface of the incisors of the Amelx* mice was rough and that the thickness of the enamel was decreased (Fig. 1D and F), whereas the enamel surface of the incisors of the WT mice was smooth (Fig. 1C and E).

Before examining the distribution of the amelogenin binding proteins, we performed a histological analysis using HE stained paraffin-embedded sections of mandible incisors of 10-week-old WT and Amelx* mice. In the incisors of the WT mice, we observed sequential ameloblast cell differentiation [i.e., preameloblasts (Fig. 2A), ameloblasts at the secretory stage (Fig. 2B), the transition stage (Fig. 2C), and the maturation stage (Fig. 2D)]. In the Amelx* mice, the regular preameloblast line (Fig. 2E) was observed. The morphology of the secretory stage ameloblasts of the Amelx* mice (Fig. 2F), including the height and cell morphology, was similar to that in WT, and the enamel matrices were stained with hematoxylin eosin, in a manner similar to the enamel matrices from WT mice. However the transition-stage ameloblasts in the Amelx* mice showed an irregular shape for the enamel matrices stained with hematoxylin eosin. In addition, the cytoplasm of the ameloblasts was also stained with hematoxilin eosin (Fig. 2G). Similar to the secretory-stage ameloblasts, the irregular ameloblasts were observed at the maturation stage in Amelx* mice and the color in the light pink enamel matrices only remained in the upper side of the ameloblasts at the maturation stage (Fig. 2H)
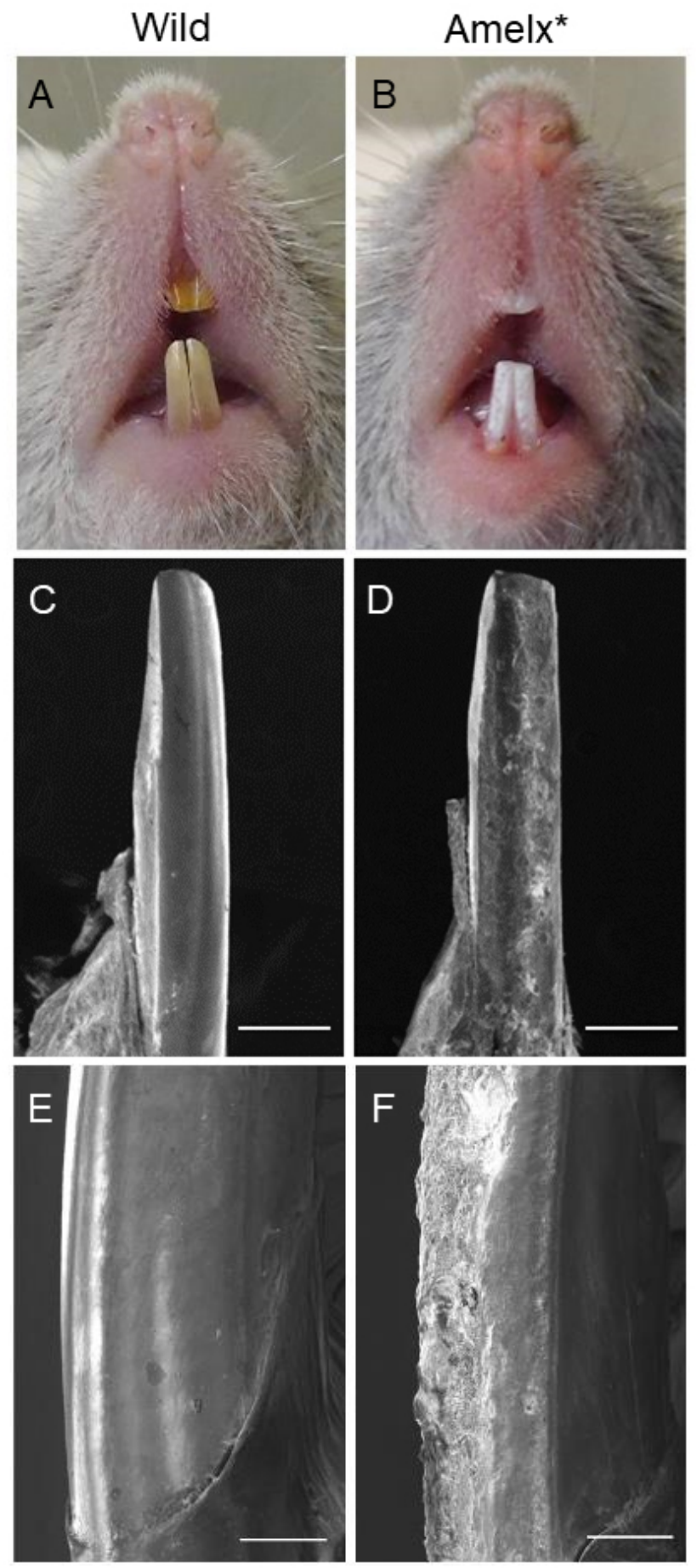

Fig. 1. The morphology of the enamel surface of the WT and Amelx* mouse incisor at 12 weeks of age. Macroscopic observation of the Amelx* mouse incisor revealed a white opaque enamel surface (B), while the WT mouse incisor was clear brown (A). Scanning electron microscopy showed that the enamel surface of the WT incisor was smooth $(\mathrm{C}, \mathrm{E})$, while the enamel of the Amelx* mouse incisor had a rough surface and its thickness was decreased (D, F). Bars in C and D $=500 \mu \mathrm{m}$; Bars in $\mathrm{E}$ and $\mathrm{F}=200 \mu \mathrm{m}$ 

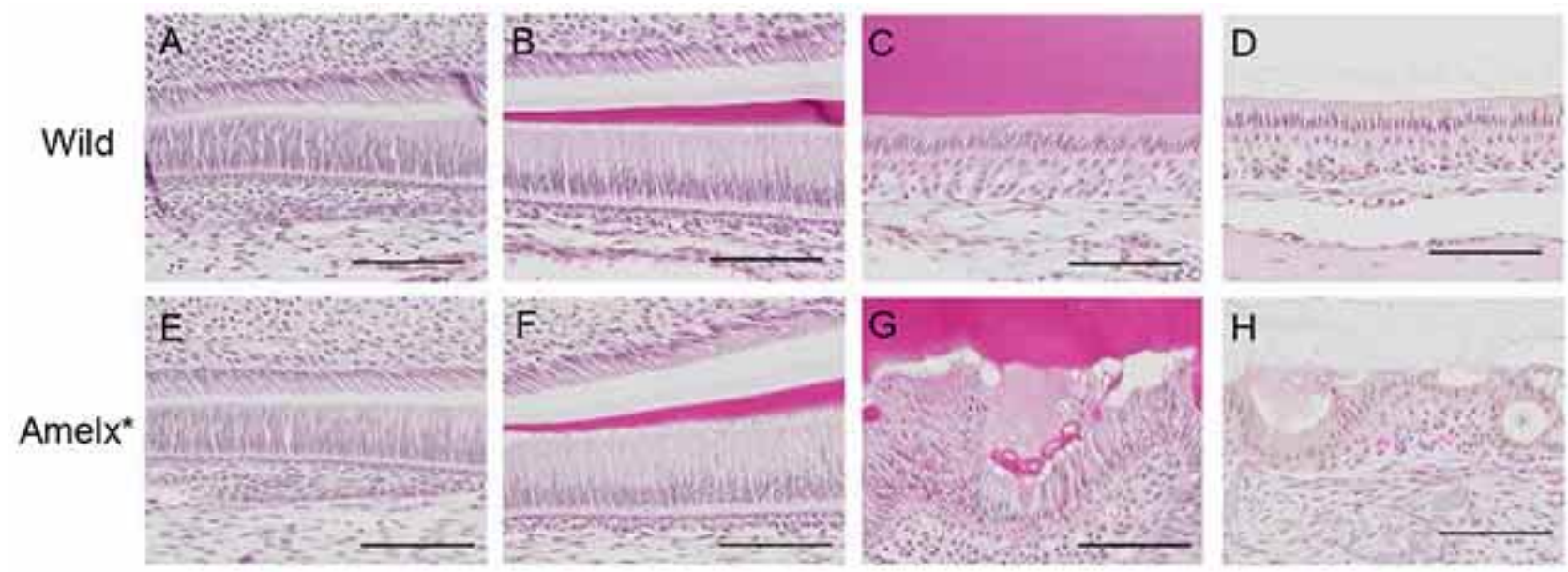

Fig. 2. The histological phenotype of Amelx* mice. The mandible incisors of 10-week-old WT and Amelx* mice were embedded in paraffin and sections were stained with HE. In the WT incisors, sequential ameloblast differentiation was observed (i.e., preameloblasts (A), and the secretory stage (B), the transition stage (C), and the maturation stage (D) ameloblasts). In the Amelx* mouse incisor, the morphology of the preameloblasts (E) and the secretory stage ameloblasts (F) was similar to that in the WT incisor. In the transition stage (G) and at the maturation stage $(\mathrm{H})$, the ameloblasts displayed an irregular shape and distribution. Bars in all $=100 \mu \mathrm{m}$

Immunostaining of Grp78 revealed that the whole cytoplasm was positive for Grp78 in the preameloblasts of both WT and Amelx* mice (Fig. 3). At the secretory stage, this whole distribution in preameloblasts changed to two dominant localization patterns: on the proximal or distal sides of the strongly WGA-positive area (Fig. 3). On the other hand, at the transition and maturation stages, whole cytoplasm of ameloblasts in the Amelx* mice was positive for Grp78 (Fig. 4), while the distal side of the ameloblasts WT mice were positive for Grp78 (Fig. 4).

Preameloblasts of the WT and Amelx* mice were both very weakly positive for LAMP-1was (Fig. 5). However, the secretory stage ameloblasts from both WT and Amelx* mice were clearly positive for LAMP-1 (Fig. 5). Regarding the distribution, the immunopositivity of the secretory stage ameloblasts was localized on the distal side of the ameloblast cytoplasm in WT mice (Fig. 5). In contrast, widespread LAMP-1 immunopositivity was observed in the cytoplasm of ameloblasts from Amelx* mice (Fig. 5). This widespread LAMP-1 immunopositivity in the cytoplasm was also observed at the transition stage in the Amelx* mice (Fig. 6). At the maturation stage, the cytoplasm of ameloblasts from WT and Amelx* mice displayed LAMP-1 immunopositivity (Fig. 6). The ameloblasts of both WT and Amelx* mice displayed LAMP-3 immunopositivity (Fig. 7) and the expanded immunopositive area was observed in the cytoplasm of several Amelx*ameloblasts (Fig. 7). However, both WT and Amelx* ameloblasts showed very low immunoreactivity to LAMP-3 at all of the stages of cell differentiation, except the transition stage, and there was no difference in the pattern of distribution between WT and Amelx* mice (data not shown).

\section{DISCUSSION}

Amelogenin is most abundant dental enamel matrix proteins and it is suggested to form an organic scaffold that is essential for regulating the enamel thickness and enamel crystallization (Wright, 2010). Defects of the dental enamel, known as AI, can be classified into three major categories (Witkop). A mutation in the Amelx gene causes hypoplastic $\mathrm{AI}$ (one of these categories) (Lagerström et al., 1991), as do mutations in other enamel matrix proteins, such as ameloblastin (Poulter et al., 2014) and enamelin (Seymen et al., 2014). Other gene mutation of enamel matrix protein like ameloblastin and enamelin cause hypoplastic AI, but amelogenin is the most important gene. LAMPs are highly glycosylated integral membrane proteins that located not only in the lysosome membrane but also on the cell surface (Saftig \& Klumperman). Grp78 is a member of heat shock protein 70 and it is associated with protein folding, protein quality control and ER stress (Daugaard et al.). Amelogenin has been reported to bind to LAMP-1, LAMP-3 (Zou et al.), and Grp78 (Fukuda et al); however, the mechanism through which is unclear these amelogenin binding proteins are involved with AI remains to be elucidated. This study attempts to reveal the localization of amelogenin binding proteins in the mice with a mutation of the Amelx gene, which exhibit AI. 

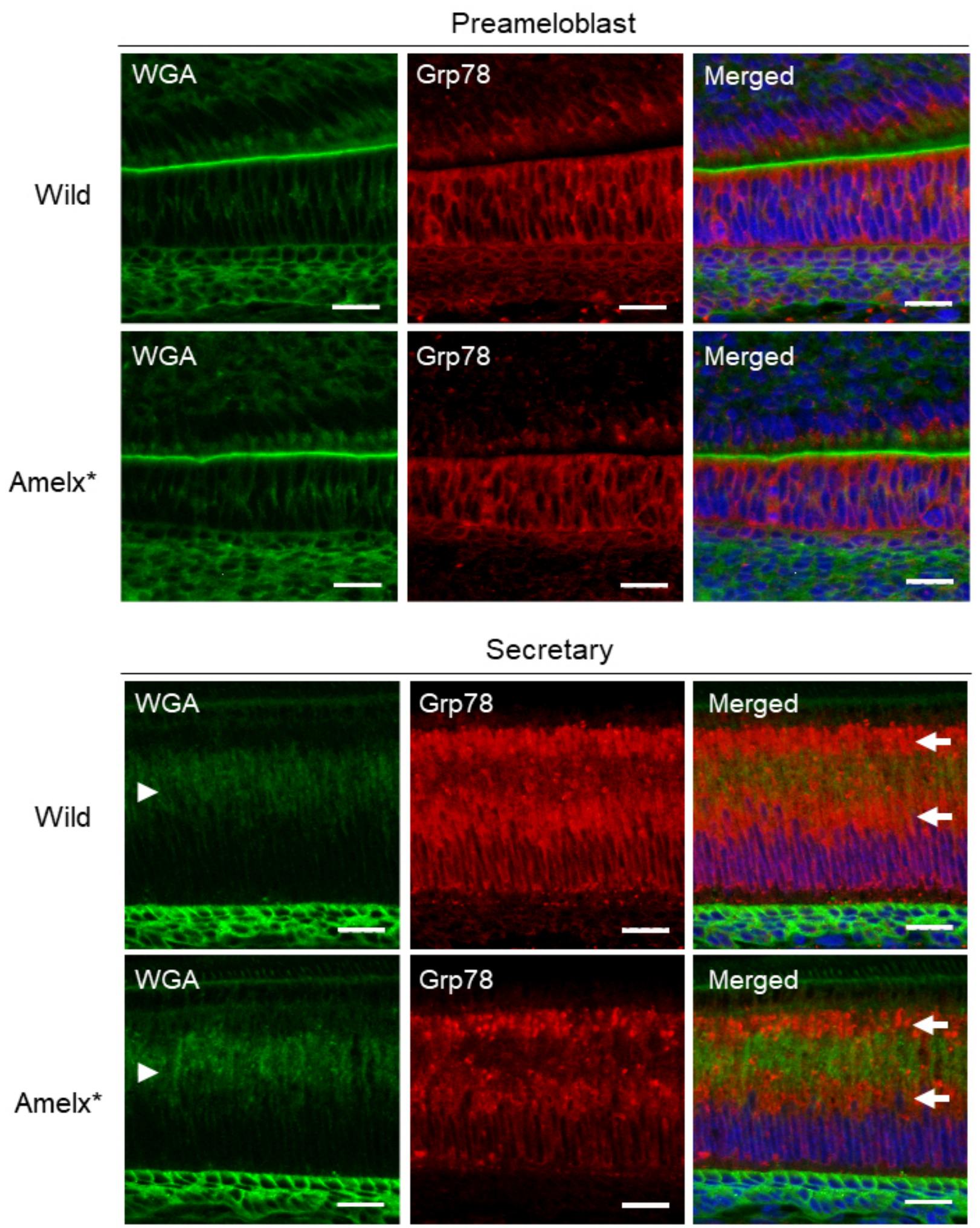

Fig. 3. Immunoreactivity to Grp78 in the preameloblasts and the secretory stage ameloblasts. Immunostaining of Grp78 (red) in the mandible incisor of 10-week-old WT and Amelx* mice was performed. To visualize the ameloblast cell morphology, lectin staining with WGA (green) was performed. Counterstaining was performed with DAPI (blue). In both WT and Amelx* mice the whole cytoplasm Grp78-positive. At the secretory stage, the distal and proximal side (arrows) of the WGA-positive area was positive for Grp78 (arrowhead). Bars in all $=20 \mu \mathrm{m}$. 


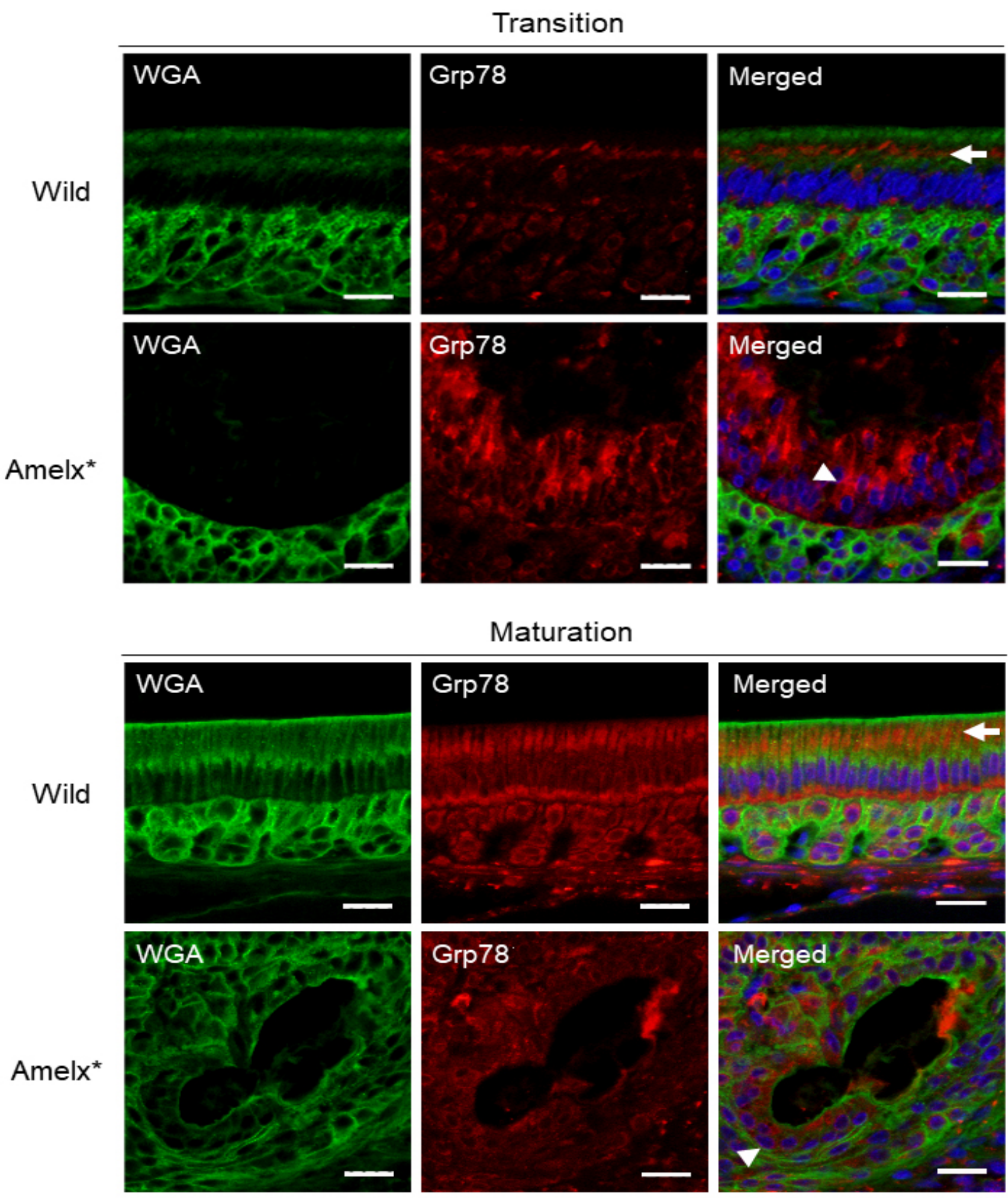

Fig. 4. Immunoreactivity to Grp78 in the transition stage and maturation stage ameloblasts. Immunostaining of Grp78 (red) in the mandible incisor of 10-week-old WT and Amelx* mice was performed. To visualize the morphology of the ameloblasts, lectin staining with WGA (green) was performed. Counterstaining was performed with DAPI (blue). In WT ameloblasts Grp78 immunopositivity was observed on the distal side of the ameloblasts at the transition and maturation stages (arrow). In contrast, in the Amelx* ameloblasts, the whole cytoplasm displayed Grp78 immunopositivity at the transition and maturation stages (arrowhead). Bars in all $=20 \mu \mathrm{m}$ 


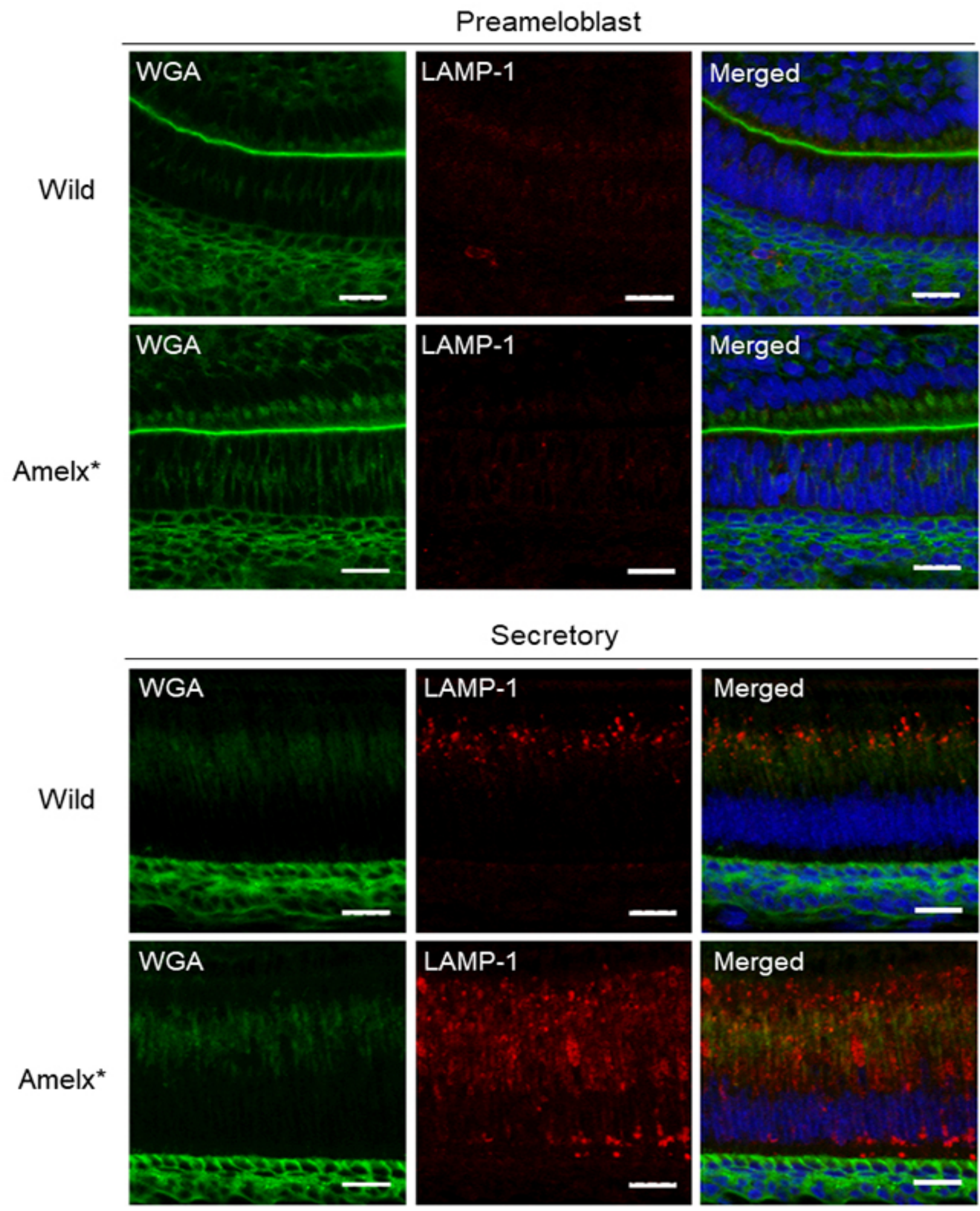

Fig. 5. Immunoreactivity to LAMP-1 in the preameloblasts and the secretory stage ameloblasts. Immunostaining of LAMP-1 (red) in the mandible incisors of 10-week-old WT and Amelx* mice was performed. To visualize the ameloblast cell morphology, lectin staining with WGA (green) was performed. Counterstaining was performed with DAPI (blue). In both WT and Amelx* mice, the preameloblasts displayed weak LAMP-1 immunoreactivity. However the cytoplasm of the secretory stage ameloblasts from Amelx* mice displayed widespread LAMP-1 immunopositivity. Bars in all $=20 \mu \mathrm{m}$ 


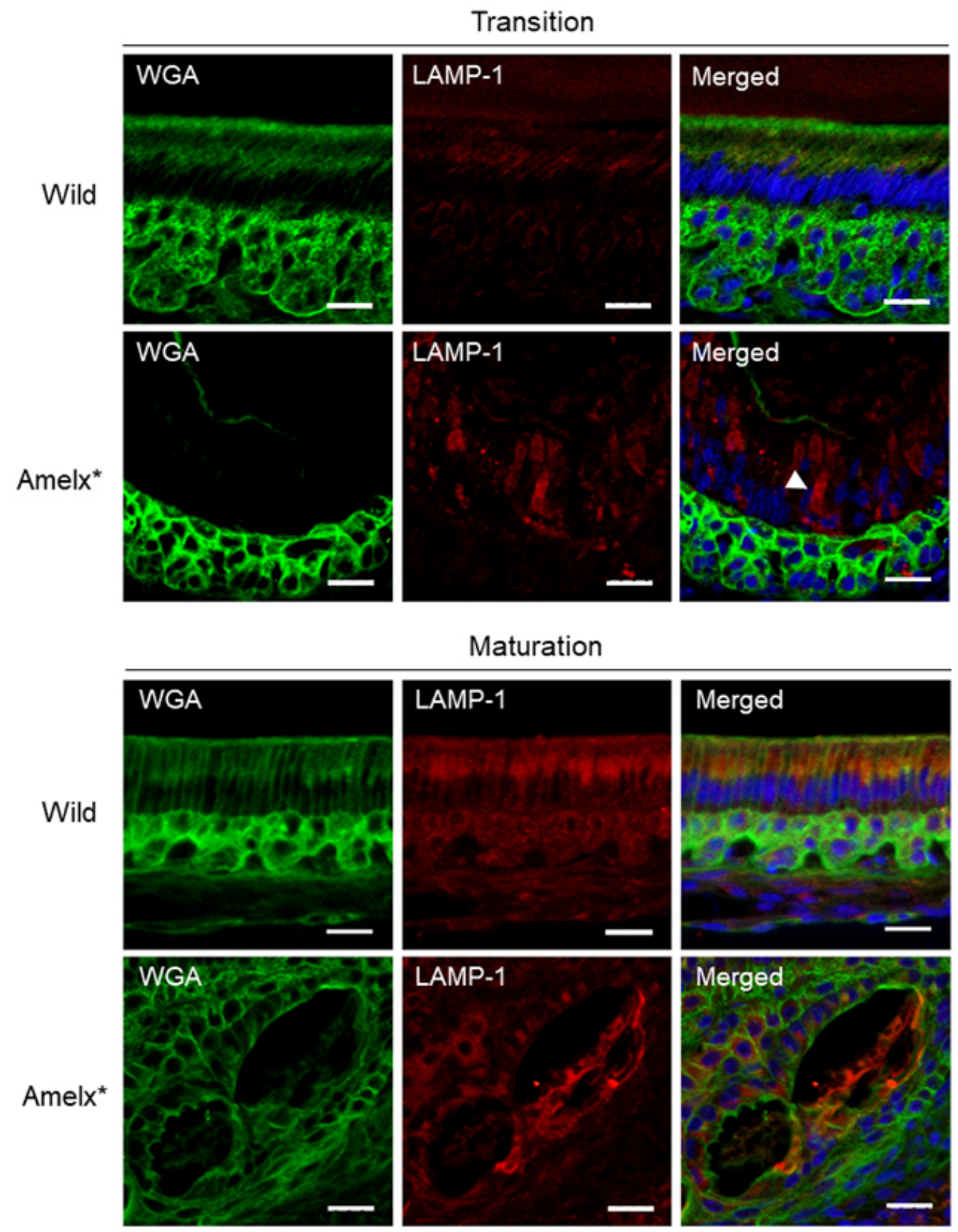

Fig. 6. Immunoreactivity to LAMP-1 in the transition and the maturation stage ameloblasts. Immunostaining of LAMP-1 (red) in the mandible incisors of 10-week-old WT and Amelx* mice was performed. To visualize the ameloblast cell morphology, lectin staining with WGA (green) was performed. Counterstaining was performed with DAPI (blue). The cytoplasm of the transition stage ameloblasts in Amelx* mice displayed LAMP-1 widespread immunopositivity (arrowhead), whereas the ameloblasts of WT mice displayed weak immunopositivity. Bars in all $=20 \mu \mathrm{m}$ 


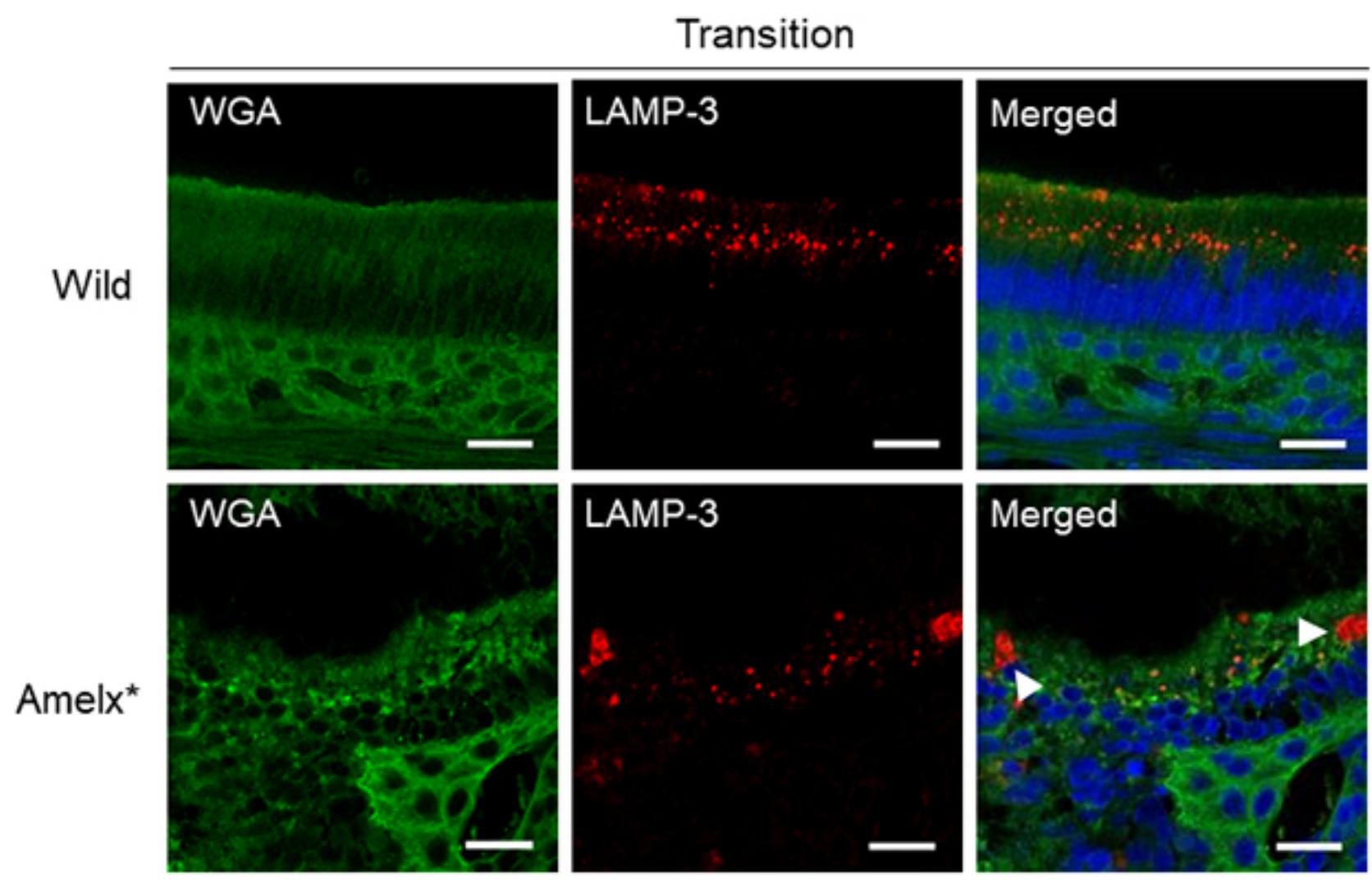

Fig. 7. Immunoreactivity to LAMP-3 in the transition stage ameloblasts. Immunostaining of LAMP-1 (red) in the mandible incisors of 10-week-old WT and Amelx* mice was performed. To visualize the ameloblast cell morphology, lectin staining with WGA (green) was performed. Counterstaining was performed with DAPI (blue). LAMP-3 immunopositivity was observed in both WT and Amelx* mice. The cytoplasm of several ameloblasts in the Amelx* mice displayed expanded immunopositivity in comparison to the WT ameloblasts (arrowhead). Bars in all $=20 \mu \mathrm{m}$

Immunostaining of these amelogenin binding proteins revealed marked Grp78 immunopositivity (Fig. 4) of the transition stage ameloblasts in the Amelx* mice, while those in the WT mice were weakly positive. Grp78 is well-known to located in the ER; however, it has been reported that various parts of the cell, including the cell surface, mitochondrion, nucleus, and cytoplasm can be positive for Grp78, and Grp78 can even be secreted into the extracellular space. Grp78 can potentially regulate a multitude of biological processes in both pathological and physiological conditions (Ni et al., 2011). In the developing tooth germ, Grp78 is predominantly expressed in the cytoplasm of preameloblasts and ameloblasts (Ravindran et al, 2012); however, there have been no reports of the Grp78 expression at sequential stages of ameloblast differentiation. Our results are consistent with those of a previous study (Ravindran et al.), in that Grp78 was detected in the cytoplasm of both preameloblasts and ameloblasts. Our study revealed that Grp78 was located in the distal part of the ameloblasts in the transition and maturation stages. On the other hand, the whole cytoplasm of Amelx* ameloblasts was positive for Grp78. This finding indicates that the point mutation of the amelogenin gene may alter the localization or increase the protein expression of Grp78. Brookes et al. (2014) reported that in the Amelx* mice (the same model as used in this study), the gene expression of Grp78 in the secretory stage ameloblasts was increased in comparison to the secretory stage ameloblasts of WT mice. Our finding showed that the distal and proximal parts of the secretory stage ameloblasts from both WT and Amelx* mice displayed Grp78 immunopositivity, and that the distribution was not markedly different. However, in the transition stage Amelx* ameloblasts the whole cytoplasm was immunopositive for Grp78, and the distribution clearly differed from that of WT ameloblasts. These results suggested that the protein expression profile of Grp78 in the ameloblasts would differ from the Grp78 gene expression in the Amelx* mice and that the point mutation of the amelogenin gene may cause the abnormal distribution of Grp78 protein in the ameloblasts. 
In addition to Grp78, the transition stage Amelx* ameloblasts displayed marked LAMP-1 immunopositivity (Fig. 6), while WT ameloblasts were weakly positive. LAMP-3 immunostaining revealed the immunopositivity of the whole cytoplasm of Amelx* ameloblasts (Fig. 7). It has been suggested that LAMP-1 and LAMP-3 on the cell membrane bind to amelogenin and could be signaling receptor of amelogenin (Veis et al., 2000; Zou et al.), and several studies have shown that LAMP-1 and LAMP-3 may be involved in the biological function of amelogenin as signaling molecules (Xu et al., 2008; Zhang et al., 2010; Kunimatsu et al., 2011; Matsuda et al., 2017). The cytoplasm of the secretory stage Amelx* ameloblasts has been reported to display strong amelogenin immunopositivity (Barron et al.). Our findings showed that the cytoplasm of the transition stage ameloblasts in the Amelx* was widely positive for LAMP-1 and LAMP-3. In the rat dental epithelial cell line, HAT-7, which is an ameloblast-like cell line, LAMP-1 is specific receptor for LRAP and is not a receptor for M180 amelogenin (Xu et al). LAMP-3 is important for the uptake of M180 by ameloblasts and is related to amelogenin degradation $(\mathrm{Xu}$ et al.). Our findings showed that LAMP-1 and -3 immunopositivity was expanded to the cytoplasm of the transition stage Amelx* ameloblasts. It suggested that the expanded distribution of LAMP-1 in the cytoplasm would depend on the increased expression of LAMP -1 and -3 proteins and that the amelogenin gene mutation could cause the production of amelogenin binding proteins. The Amelx* mice in this study were established via a point mutation of amelogenin that affected TRAP, which is small amelogenin peptide and a product of proteolytic degradation. The gene and protein expression of M180 and LRAP in the Amelx* mice remain unclear. Further studies are needed to clarify the relationship between the encoding of the point mutation according to TRAP and the expression of the other amelogenin splicing isoform.

\section{ACKNOWLEDGEMENTS}

This work was supported by a Grant-in-Aid for Scientific Research (C) from the Ministry of Education, Culture, Sports, Science and Technology, Japan, to YH (23592726).

OTAWA-KAMOGASHIRA, N.; MATSUDA, Y.; TAKEZAKI, M.; HATAKEYAMA, YUJI; TAMAOKI, S. \& ISHIKAWA, H. Estudio inmunohistoquímico de proteínas de unión de la amelogenina en un ratón con mutación puntual de amelogenina. Int. J. Morphol., 37(2):522-532, 2019.
RESUMEN: La amelogenina es una de las matrices de esmalte secretadas por los ameloblastos. Una mutación del gen de amelogenina puede causar defectos hereditarios del esmalte dental conocidos como amelogénesis imperfecta (AI). Dado que la proteína de membrana asociada a lisosoma-1 (LAMP-1), -3 (LAMP-3) y la proteína relacionada con la glucosa de $78 \mathrm{kDa}$ (Grp78) se identificaron como proteína de unión a amelogenina, varios estudios han sugerido la participación de estas proteínas con la cinética celular de los ameloblastos en condiciones normales o anormales. El objetivo del estudio fue investigar la distribución de LAMP-1, LAM-3 y Grp78 durante la diferenciación celular de ameloblastos de ratones con una mutación puntual del gen de amelogenina (Amelx*). Los incisivos de los ratones Amelx* presentaron un color blanco opaco y se observó en microscopio electrónico de barrido que la superficie del diente era áspera. La diferenciación celular secuencial y la forma de los ameloblastos en la etapa de transición en los ratones Amelx* fue irregular en comparación con los ratones silvestres (RS). La inmunotinción de Grp78 reveló que todo el citoplasma de los ameloblastos en etapa de transición fue inmunopositivo para el anticuerpo Grp78, mientras que solo la parte distal de la célula fue positiva en los ratones RS. Además, en ratones Amelx*, el citoplasma de los ameloblastos en etapa de transición fue inmunopositivo para LAMP-1 y LAMP-3. Estos resultados sugieren que Amelx* puede causar distribución anormal de proteínas de unión a amelogenina en el citoplasma de los ameloblastos.

PALABRAS CLAVE: Amelogenina; Amelogenesis imperfecta; Proteína relacionada con la glucosa de $78 \mathrm{kDa}$ (Grp78); Proteínas de membrana asociadas a los lisosomas (LAMP).

\section{REFERENCES}

Akita, H.; Kobayashi, Y. \& Kagayama, M. A histochemical study on lectin binding in the immature enamel and secretory ameloblasts of rat incisors. Tohoku J. Exp. Med., 155(2):139-49, 1988.

Bai, Y.; Wei, Y.; Wu, L.; Wei, J.; Wang, X. \& Bai, Y. C/EBP b mediates endoplasmic reticulum stress regulated inflammatory response and extracellular matrix degradation in LPS-stimulated human periodontal ligament cells. Int. J. Mol. Sci., 17(3):385, 2016.

Barron, M. J.; Brookes, S. J.; Kirkham, J.; Shore, R. C.; Hunt, C.; Mironov, A.; Kingswell, N. J.; Maycock, J.; Shuttleworth, C. A. \& Dixon, M. J. A mutation in the mouse Amelx tri-tyrosyl domain results in impaired secretion of amelogenin and phenocopies human X-linked amelogenesis imperfecta. Hum. Mol. Genet., 19(7):1230-47, 2010.

Brookes, S. J.; Barron, M. J.; Boot-Handford, R.; Kirkham, J. \& Dixon, M. J. Endoplasmic reticulum stress in amelogenesis imperfecta and phenotypic rescue using 4-phenylbutyrate. Hum. Mol. Genet., 23(9):2468-80, 2014.

Chazotte, B. Labeling membrane glycoproteins or glycolipids with fluorescent wheat germ agglutinin. Cold Spring Harb. Protoc., 2011(5):pdb.prot5623, 2011.

Daugaard, M.; Rohde, M. \& Jäättelä, M. The heat shock protein 70 family: Highly homologous proteins with overlapping and distinct functions. F. E. B. S. Lett., 581(19):3702-10, 2007.

Fukuda, T.; Sanui, T.; Toyoda, K.; Tanaka, U.; Taketomi, T.; Uchiumi, T. \& Nishimura, F. Identification of novel amelogenin-binding proteins by proteomics analysis. PLoS One, 8(10):e78129, 2013. 
Haruyama, N.; Hatakeyama, J.; Hatakeyama, Y.; Gibson, C. W. \& Kulkarni, A. B. Lessons from the Amelogenin Knockout Mice. In: Goldberg, M. (Ed.). Amelogenins: Multifaceted Proteins for Dental \& Bone Formation \& Repair. Soest, Bentham Science Publishers, 2010. pp.25-31.

Hatakeyama, Y.; Hatakeyama, J.; Oka, K.; Tsuruga, E.; Inai, T.; Anan, H. \& Sawa, Y. Immunohistochemical study of amelogenin and LysosomeAssociate Membrane Proteins (LAMPs) in cartilage. Int. J. Morphol., 32(2):618-26, 2014.

Herzog, C. R.; Reid, B. M.; Seymen, F.; Koruyucu, M.; Tuna, E. B.; Simmer, J. P. \& Hu, J. C. Hypomaturation amelogenesis imperfecta caused by a novel SLC24A4 mutation. Oral Surg. Oral Med. Oral Pathol. Oral Radiol.,119(2):e77-81, 2015.

Kagayama, M.; Zhu, J. X.; Sasano, Y.; Sato, H. \& Mayanagi, H. Development of interglobular dentine in rat molars and its relation to maturation of enamel. Anat. Embryol. (Berl.), 196(6):477-83, 1997.

Kunimatsu, R.; Tanimoto, K.; Tanne, Y.; Kamiya, T.; Ohkuma, S.; Huang, Y. C.; Yoshimi, Y.; Miyauchi, M.; Takata, T. \& Tanne, K. Amelogenin enhances the proliferation of cementoblast lineage cells. J. Periodontol., 82(11):1632-8, 2011.

Lagerström, M.; Dahl, N.; Nakahori, Y.; Nakagome, Y.; Bäckman, B.; Landegren, U. \& Pettersson, U. A deletion in the amelogenin gene (AMG) causes X-linked amelogenesis imperfecta (AIH1). Genomics, 10(4):971-5, 1991.

Le, T. Q.; Zhang, Y.; Li, W. \& Denbesten, P. K. The effect of LRAP on enamel organ epithelial cell differentiation. J. Dent. Res., 86(11):1095$9,2007$.

Matsuda, Y.; Hatakeyama, Y.; Nakashima, K.; Kamogashira, N.; Hatakeyama, J.; Sachio, T.; Sawa, Y. \& Ishikawa, H. Effects of a Chemically Synthesized Leucine-Rich Amelogenin Peptide (csLRAP) on chondrogenic and osteogenic cells. J. Hard Tissue Biol., 26(1):51-60, 2017.

Ni, M.; Zhang, Y. \& Lee, A. S. Beyond the endoplasmic reticulum: atypical GRP78 in cell viability, signalling and therapeutic targeting. Biochem. J., 434(2):181-8, 2011.

Poulter, J. A.; Murillo, G.; Brookes, S. J.; Smith, C. E.; Parry, D. A.; Silva, S.; Kirkham, J.; Inglehearn, C. F. \& Mighell, A. J. Deletion of ameloblastin exon 6 is associated with amelogenesis imperfecta. Hum. Mol. Genet., 23(20):5317-24, 2014

Ravindran, S.; Gao, Q.; Ramachandran, A.; Sundivakkam, P.; Tiruppathi, C. $\&$ George, A. Expression and distribution of grp-78/bip in mineralizing tissues and mesenchymal cells. Histochem. Cell Biol., 138(1):113-25, 2012.

Saftig, P. \& Klumperman, J. Lysosome biogenesis and lysosomal membrane proteins: trafficking meets function. Nat. Rev. Mol. Cell Biol., 10(9):62335, 2009.

Seymen, F.; Lee, K. E.; Koruyucu, M.; Gencay, K.; Bayram, M.; Tuna, E. B.; Lee, Z. H. \& Kim, J. W. ENAM mutations with incomplete penetrance. J. Dent. Res., 93(10):988-92, 2014.

Veis, A.; Tompkins, K.; Alvares, K.; Wei, K.; Wang, L.; Wang, X. S.; Brownell, A. G.; Jengh, S. M. \& Healy, K. E. Specific amelogenin gene splice products have signaling effects on cells in culture and in implants in vivo. J. Biol. Chem., 275(52):41263-72, 2000.

Witkop, C. J. Jr. Amelogenesis imperfecta, dentinogenesis imperfecta and dentin dysplasia revisited: problems in classification. J. Oral Pathol., 17(9-10):547-53, 1988.

Wright, J. T. Consequences of Amelogenin Mutations: Implications in Amelogenesis Imperfecta. In: Goldberg, M. (Ed.). Amelogenins: Multifaceted Proteins for Dental \& Bone Formation \& Repair. Soest, Bentham Science Publishers, 2010. pp.88-98.

$\mathrm{Xu}, \mathrm{L}$.; Harada, H. \& Taniguchi, A. The effects of LAMP1 and LAMP3 on M180 amelogenin uptake, localization and amelogenin mRNA induction by amelogenin protein. J. Biochem., 144(4):531-7, 2008

Zhang, H.; Tompkins, K.; Garrigues, J.; Snead, M. L.; Gibson, C. W. \& Somerman, M. J. Full length amelogenin binds to cell surface LAMP1 on tooth root/periodontium associated cells. Arch. Oral Biol., 55(6):417-25, 2010.
Zhang, Y.; Zhang, K.; Ma, L.; Gu, H.; Li, J. \& Lei, S. Fluoride induced endoplasmic reticulum stress and calcium overload in ameloblasts. Arch. Oral Biol., 69:95-101, 2016.

Zou, Y.; Wang, H.; Shapiro, J. L.; Okamoto, C. T.; Brookes, S. J.; Lyngstadaas, S. P.; Snead, M. L. \& Paine, M. L. Determination of protein regions responsible for interactions of amelogenin with CD63 and LAMP1. Biochem. J., 408(3):347-54, 2007.

\section{Corresponding autor:}

Yuji Hatakeyama,

Department of Morphological Biology

Fukuoka Dental College, 2-15-1

Tamura, Sawara-ku,

Fukuoka, 814-0193

JAPAN

\section{E-mail: hatakeyy@college.fdcnet.ac.jp}

Received: 22-11-2018

Accepted: 07-01-2019 